\title{
Dietary iron concentration influences serum concentrations of manganese in rats consuming organic or inorganic sources of manganese
}

\author{
Huaiyong Zhang ${ }^{1}$, Elizabeth R. Gilbert ${ }^{2}$, Shuqin Pan ${ }^{1}$, Keying Zhang ${ }^{1}$, Xuemei Ding ${ }^{1}$, Jianping Wang ${ }^{1}$, \\ Qiufeng Zeng ${ }^{1}$ and Shiping Bai ${ }^{1 *}$ \\ ${ }^{1}$ Animal Nutrition Institute, Sichuan Agricultural University, 46 Xinkang Road, Ya'an 625014, Sichuan, People's Republic \\ of China \\ ${ }^{2}$ Department of Animal and Poultry Sciences, Virginia Tech University, Blacksburg, VA 24061, USA
}

(Submitted 12 July 2015 - Final revision received 25 October 2015 - Accepted 30 October 2015 - First published online 21 December 2015)

\section{Abstract}

To determine the effects of dietary Fe concentration on Mn bioavailability in rats fed inorganic or organic Mn sources, fifty-four 22-d-old male rats were randomly assigned and fed a basal diet (2.63 mg Fe/kg) supplemented with 0 (low Fe (L-Fe)), 35 (adequate Fe (A-Fe)) or 175 (high $\mathrm{Fe}(\mathrm{H}-\mathrm{Fe})) \mathrm{mg} \mathrm{Fe} / \mathrm{kg}$ with $10 \mathrm{mg} \mathrm{Mn} / \mathrm{kg}$ from $\mathrm{MnSO}_{4}$ or Mn-lysine chelate (MnLys). Tissues were harvested after $21 \mathrm{~d}$ of feeding. Serum Mn was greater $(P<0.05)$ in MnLys rats than in $\mathrm{MnSO}_{4}$ rats, and in L-Fe rats than in A-Fe or H-Fe rats. Duodenal divalent metal transporter-1 (DMT1) mRNA was lower $(P<0.05)$ in $\mathrm{H}-\mathrm{Fe}$ rats than in A-Fe rats for the $\mathrm{MnSO}_{4}$ treatment; however, no significant difference was observed between them for MnLys. Liver DMT1 mRNA abundance was greater $(P<0.05)$ in $\mathrm{MnSO}_{4}$ than in the MnLys group for H-Fe rats. The DMT1 protein in duodenum and liver and ferroportin 1 (FPN1) protein in liver was greater $(P<0.05)$ in the $\mathrm{MnSO}_{4}$ group than in the MnLys group, and in L-Fe rats than in H-Fe rats. Duodenal FPN1 protein was greater $(P<0.05)$ in L-Fe rats than in A-Fe rats for the MnLys treatment, but it was not different between them for the $\mathrm{MnSO}_{4}$ treatment. Results suggest that MnLys increased serum Mn concentration as compared with $\mathrm{MnSO}_{4}$ in rats irrespective of dietary Fe concentration, which was not because of the difference in DMT1 and FPN1 expression in the intestine and liver.

Key words: Dietary manganese: Manganese-lysine chelate: Serum manganese: Dietary iron: Rats

Iron deficiency (ID) may affect as many as two billion people worldwide $^{(1)}$. It is especially common in pregnant women and young children ${ }^{(2)}$. Although ID is easily treated with $\mathrm{Fe}$ supplementation, excess $\mathrm{Fe}$ is associated with homoeostatic dysregulation of other metals, including $\mathrm{Mn}^{(3-5)}$. The Fe-overload diet reduced the absorption of inorganic Mn, thereby lowering the Mn status in rats ${ }^{(6,7)}$ and pigs ${ }^{(8)}$. Recently, several commercial organic Mn sources including metal-amino acid complexes have been developed as supplements in livestock and poultry feed, and results from many studies demonstrated that organic Mn sources were more bioavailable than traditional Mn sulphate in pigs ${ }^{(9,10)}$ and using Caco-2 cells ${ }^{(11)}$. However, there are no reports on the influence of dietary Fe concentration on the metabolism of Mn from an organic dietary Mn source.

Over the past decade, there have been several advances in our understanding of the molecular mechanisms involved in $\mathrm{Fe}$ absorption. In particular, two Fe transport proteins have been well characterised using in vitro and rodent models: the cellular Fe importer, divalent metal transporter-1 (DMT1), and cellular Fe exporter, ferroportin 1 (FPN1 $)^{(12,13)}$. Recent studies have documented a role for DMT1 in Mn uptake ${ }^{(14-16)}$ and the Fe exporter FPN1 in transporting Mn out of cells ${ }^{(17,18)}$. High dietary $\mathrm{Fe}(500 \mathrm{mg} \mathrm{Fe} / \mathrm{kg}$ ) decreased DMT1 expression in the intestine of pigs, which might have reduced $\mathrm{Mn}$ absorption ${ }^{(8)}$. Therefore, the aims of this study were (1) to compare the effects of dietary Fe concentration on Mn bioavailability in rats fed inorganic and organic Mn sources, and to (2) determine the effects of different Mn sources on potential Mn transporter expression in the duodenum and liver. We hypothesised that organic Mn would improve Mn bioavailability in rats, and that alterations in duodenal and hepatic DMT1 and FPN1 expression would be associated with differences in Mn bioavailability.

\section{Methods}

\section{Animals, diets and experimental design}

Care, handling and sampling procedures were approved by the Animal Care and Use Committee of Sichuan Agricultural University before initiation of the trial. A total of fifty-four

Abbreviations: A-Fe, adequate Fe; DMT1, divalent metal transporter-1; FPN1, ferroportin 1; HAMP, hepcidin; H-Fe, high Fe; L-Fe, low Fe; MnLys, Mn-lysine chelate.

* Corresponding author: Dr S. Bai, fax +86 8352885 630, email shipingbai@sicau.edu.cn 
Table 1. Ingredient and nutrient composition of the basal diet

\begin{tabular}{|c|c|}
\hline Items & Content \\
\hline \multicolumn{2}{|l|}{ Ingredient $(\mathrm{g} / \mathrm{kg})$} \\
\hline Casein & $200 \cdot 0$ \\
\hline L-Cystine & $3 \cdot 0$ \\
\hline Maize starch & $397 \cdot 5$ \\
\hline Cellulose & $50 \cdot 0$ \\
\hline Maltodextrin & $132 \cdot 0$ \\
\hline Sucrose & $100 \cdot 0$ \\
\hline Soyabean oil & $70 \cdot 0$ \\
\hline Mineral mix ${ }^{*}$ & $35 \cdot 0$ \\
\hline Vitamin mix $†$ & $10 \cdot 0$ \\
\hline Choline chloride & $2 \cdot 5$ \\
\hline \multicolumn{2}{|l|}{ Nutrients levels $\ddagger$} \\
\hline $\mathrm{Mn}(\mathrm{mg} / \mathrm{kg})$ & $1 \cdot 31$ \\
\hline $\mathrm{Fe}(\mathrm{mg} / \mathrm{kg})$ & $2 \cdot 68$ \\
\hline \multicolumn{2}{|c|}{$\begin{array}{l}{ }^{*} \text { Provided (per } \mathrm{kg} \text { of diet): } 5000 \mathrm{mg} \mathrm{Ca} \text { (as calcium carbonate, anhydrous), } 1600 \mathrm{mg} \\
\mathrm{P} \text { (as potassium dihydrogen phosphate), } 3600 \mathrm{mg} \mathrm{K} \text { (as potassium chloride), } \\
1300 \mathrm{mg} \mathrm{Na} \text { (as sodium chloride), } 500 \mathrm{mg} \mathrm{Mg} \mathrm{(as} \mathrm{magnesium} \mathrm{oxide),} 35 \mathrm{mg} \mathrm{Zn} \mathrm{(as} \\
\text { zinc chloride), } 6 \mathrm{mg} \mathrm{Cu} \text { (as copper (II) chloride dehydrate), } 0.21 \mathrm{mg} \text { I (as potassium } \\
\text { iodate), } 0.17 \mathrm{mg} \text { Se (as sodium selenite, anhydrous). }\end{array}$} \\
\hline \multicolumn{2}{|c|}{$\begin{array}{l}\text { Provided (per } \mathrm{kg} \text { of diet): } 0.1 \mathrm{mg} \text { cholecalciferol, } 60 \mathrm{mg} \text { a-tocopherol acetate, } \\
15 \mathrm{mg} \text { thiamin, } 10 \mathrm{mg} \text { pyridoxine, } 15 \mathrm{mg} \text { riboflavin, } 10 \mathrm{mg} \text { folic acid, } 10 \mathrm{mg} \text { biotin, } \\
10 \mathrm{mg} \text { menadione, } 4 \mathrm{mg} \text { retinol, } 1 \mathrm{mg} \text { cyanocobalamin, } 30 \mathrm{mg} \text { nicotinic acid, } 50 \mathrm{mg} \\
\text { pantothenic acid. }\end{array}$} \\
\hline
\end{tabular}

$\ddagger$ Analysed values.

22-d-old weanling male Sprague-Dawley rats were used in a 21-d trial. The rats with mean 57.2 (SD 3.1) g average body weight were randomly assigned to one of six treatments ( $n$ $9 /$ treatment) in a $3 \times 2$ factorial design with 3 concentrations of dietary Fe (no supplemental Fe (low Fe (L-Fe)), $35 \mathrm{mg}$ of supplemental $\mathrm{Fe}$ (adequate $\mathrm{Fe}(\mathrm{A}-\mathrm{Fe}))$ and $175 \mathrm{mg}$ of supplemental $\mathrm{Fe}$ (high $\mathrm{Fe}(\mathrm{H}-\mathrm{Fe}))$ ) and 2 dietary $\mathrm{Mn}$ sources $\left(\mathrm{MnSO}_{4}\right.$ and $\mathrm{Mn}-$ lysine complex (MnLys)). Supplemental Fe was provided as $\mathrm{FeSO}_{4} \cdot \mathrm{H}_{2} \mathrm{O}$ and $\mathrm{Mn}$ was supplemented at a dose of $10 \mathrm{mg} \mathrm{Mn} / \mathrm{kg}$ diet. The MnLys is a compound with one atom of Mn chelated by two molecules of L-lysine, and it contains $13.8 \%$ Mn (Chengdu Amino Acids Chelation Biotechnology Co. Ltd). In the MnLys molecules, the lysine binds in what is known as a glycinato manner, where a five-membered ring is formed with metal amino nitrogen and carboxylic oxygen ${ }^{(19)}$. The basal diet was formulated based on a modified AIN93G diet, according to recommendations ${ }^{(20)}$ to meet the rat's requirement for all nutrients except Fe (Table 1), and it was pelleted. The basal diet contained $2.63 \mathrm{mg} \mathrm{Fe} / \mathrm{kg}$ diet and $1.31 \mathrm{mg} \mathrm{Mn} / \mathrm{kg}$ diet by analysis. Rats were housed individually in an environmentally controlled room and consumed feed and water ad libitum. Rat weights were recorded on $\mathrm{d} 0$ and 21. Feed consumption was recorded and feed:gain was calculated during the 21-d feeding period.

\section{Sample collection}

On d 21, all rats were diethyl ether anaesthetised after overnight food withdrawal, and blood was collected via cardiac puncture. Blood for $\mathrm{Hb}$ determination was collected in heparinised vacuum tubes and transferred to ice for analysis. Blood for serum parameter analysis was collected in vacuum tubes and allowed to clot at room temperature for $2 \mathrm{~h}$ before centrifugation. After blood collection, all rats were euthanised by cervical dislocation. A 4-cm segment of the duodenum (beginning from
$2 \mathrm{~cm}$ distal to the pyloric sphincter) was removed, cut open longitudinally along the antimesenteric border and rinsed with ice-cold $0.9 \%$ saline to remove digesta before tissue collection. The first $2 \mathrm{~cm}$ of exposed duodenal mucosa was scraped, and scrapings were immediately flash-frozen in liquid $\mathrm{N}_{2}$ for RNA and protein analysis. The mucosa of the remaining duodenal segment was scraped and stored at $-20^{\circ} \mathrm{C}$ for mineral determination. One liver sample was rinsed thoroughly with PBS to remove hepatic blood contamination, wrapped in aluminium foil and flash-frozen in liquid $\mathrm{N}_{2}$, and another was stored at $-20^{\circ} \mathrm{C}$ for mineral determination.

\section{Blood and mineral analysis}

Blood was analysed for $\mathrm{Hb}$ concentration using Drabkin's reagent kits (Nanjing Jiancheng Bioengineering Institute). Serum total Fe-binding capacity (TIBC) was determined by colorimetric diagnostic kits (Nanjing Jiancheng Bioengineering Institute). Blood for serum analysis was centrifuged at $3500 \mathrm{~g} / 15 \mathrm{~min}$ at $20^{\circ} \mathrm{C}$, and serum was prepared for mineral analysis as previously described ${ }^{(21)}$. Feed, liver and mucosal scraping samples were prepared for Mn determination by the wet ashing method using microwave digestion (Mars 5; CEM Corporation), as previously described ${ }^{(22)}$. The Mn concentrations in serum, feed and tissues and serum Fe concentrations were determined by graphite furnace atomic absorption spectroscopy (PerkinElmer AA800; PerkinElmer Inc.). A bovine liver standard (NBS Standard Reference Material, USDC, Washington, DC, USA) was included in all analyses to verify the determination accuracy. The non-haeme Fe concentration in duodenal scrapings and liver was measured as described ${ }^{(23)}$. Briefly, liver and duodenal scraping samples (approximately $100 \mu \mathrm{g}$ ) were digested in $2 \mathrm{ml}$ of a mixture of equal volumes of 6 m-hydrochloric acid and $20 \%$ TCA at $65^{\circ} \mathrm{C}$ for $20 \mathrm{~h}$. After cooling to room temperature, the clear yellow solution was transferred to a test tube and a colour reagent $(0 \cdot 1 \%$ sulphonated bathophenanthroline mixed with $1 \%$ thioglycolic acid and distilled water at 1:25:25 ratio) was added. After 10-min incubation, the optical density was measured at $540 \mathrm{~nm}$. A standard curve was prepared using an Fe standard solution (Nanjing Jiancheng Bioengineering Institute). The Fe concentration in tissue was expressed as $\mu \mathrm{g} / \mathrm{g}$ wet tissue.

\section{RNA isolation and real-time PCR}

Total RNA was extracted from snap-frozen duodenum using Trizol reagent (Invitrogen) according to the manufacturer's instructions. The RNA quality (intact ribosomal RNA 28s/18s) was evaluated by agarose gel electrophoresis, and RNA concentrations were quantified using a spectrophotometer (NanoDrop 2000; Thermo Fisher Scientific Inc.). First-strand complementary DNA (cDNA) was reverse-transcribed from 200 ng of total RNA using the PrimeScript ${ }^{\mathrm{TM}}$ RT Reagent Kit (Takara). Real-time PCR was performed in triplicate on an ABI 7500 Real-Time PCR detection system (Applied Biosystems). Real-time PCR was performed in 10- $\mu$ l volume reactions that contained $3 \mu \mathrm{l}$ of 10 -fold diluted cDNA, $1 \mu \mathrm{l}$ each of $5 \mu \mathrm{M}$ forward and reverse primers and $5 \mu \mathrm{l}$ of $1 \times$ SYBR Green Master Mix (Takara). The cycling program was $95^{\circ} \mathrm{C} / 15 \mathrm{~min}$, followed 
by forty cycles of $95^{\circ} \mathrm{C} / 5 \mathrm{~s}$ and $60^{\circ} \mathrm{C} / 30 \mathrm{~s}$, and a final melting curve analysis. The primer sequences for DMT1, FPN1, transferrin receptor 1 (TFR1), hepcidin (HAMP) and $\beta$-actin are displayed in online Supplementary Table S1. Gene-specific amplification was determined by melting curve analysis and agarose gel electrophoresis. Relative quantities of mRNA were calculated using the $2^{-\Delta \Delta C_{t}}$ method with the quantity of the A-Fe with $\mathrm{MnSO}_{4}$ diet group scaled to $1^{(24)}$. Three housekeeping genes (glyceraldehyde-3-phosphate dehydrogenase, ribosomal protein S9 and $\beta$-actin) were assessed for stability of expression using two separate cDNA from each treatment (data not shown). The $\beta$-actin was subsequently selected as the reference gene ${ }^{(11,21)}$.

\section{Protein extraction and immunoblotting}

The isolation of protein from duodenal scrapings and liver was performed as previously described ${ }^{(8)}$. Briefly, approximately $0.4 \mathrm{~g}$ of tissue sample was homogenised supersonically in $3 \mathrm{ml}$ of lysis buffer (20 mu-Tris- $\mathrm{HCl}, 150 \mathrm{~mm}-\mathrm{NaCl}, 2 \mathrm{~mm}-\mathrm{Na}_{2}$ EDTA, $1 \%$ NP-40 (v/v), $0 \cdot 5 \%$ sodium deoxycholate (w/v), $0 \cdot 1 \%$ SDS (w/v) and a protease inhibitor cocktail). After centrifugation at $10000 \boldsymbol{g}$ for $30 \mathrm{~min}$ at $4^{\circ} \mathrm{C}$, the supernatant was collected. Protein concentrations in the supernatant were determined using bicinchoninic acid protein assay kits (Thermo Fisher Scientific Inc.).

For Western blot analysis, all supplies and reagents were from Bio-Rad Laboratories Inc. and all antibodies and positive control proteins were from Santa Cruz Biotechnology Inc., unless otherwise stated. In total, $40 \mu \mathrm{g}$ of protein was loaded into each well after heating for $5 \mathrm{~min}$ at $95^{\circ} \mathrm{C}$. Proteins were separated by $10 \%$ SDS-PAGE at $125 \mathrm{~V}$ for $90 \mathrm{~min}$ and transferred onto a polyvinylidene diflouride membrane at $20 \mathrm{~V}$ for 5 min (Trans Blot Turbo transfer system; Bio-Rad). Molecular weight standards (Takara) were loaded in parallel on each gel. Similar loading and transfer of proteins were verified by staining the blots with Ponceau S (Sigma-Aldrich) after transfer. Membranes were blocked using 5\% non-fat milk in a solution of Tris-buffered salt with Tween-20 (TBST; $137 \mathrm{~mm}-\mathrm{NaCl}, 2.7 \mathrm{~mm}-$ $\mathrm{KCl}, 19 \mathrm{~mm}$-Tris- $\mathrm{HCl} \mathrm{pH} 7.5$ and $0.1 \%$ Tween-20) for $2 \mathrm{~h}$ at room temperature. The membranes were then probed with polyclonal goat anti-FPN1 (catalogue no. sc-49668; dilution 1:500) or rabbit anti-DMT1 (catalogue no. sc-30120; dilution 1:100) overnight at $4^{\circ} \mathrm{C}$. After incubation with the primary antibody, and washing with TBST buffer (three times; 15 min each time), membranes were incubated with goat anti-rabbit (catalogue no. sc-2004; dilution 1:5000) or donkey anti-goat (catalogue no. sc-2020; dilution 1:5000) secondary antibody-conjugated horseradish peroxidase for $2 \mathrm{~h}$ at room temperature. After washing with TBST (three times; 15 min each time) and water (two times; 5 min each time), the signal of membranes was visualised by enhanced chemiluminescence (ECL) (PerkinElmer). The human neuroblastoma cell lysate (catalogue no. sc-2409) and human jejunum smooth muscle cells (catalogue no. sc-2229) were used as the positive controls for DMT1 and FPN1 protein determination, respectively. The blots were detected using the chemiluminescence imaging system (ChemiDoc MP System; Bio-Rad) and quantified by transmittance densitometry using volume integration with the ImageJ analysis software (National Institutes of Health). After ECL detection, the membranes were incubated at $50^{\circ} \mathrm{C}$ for $30 \mathrm{~min}$ in stripping solution $(100 \mathrm{mmol} / \mathrm{l}$ $\beta$-mercaptoethanol, $2 \%$ SDS, $62.5 \mathrm{mmol} / \mathrm{l}$ Tris-HCl, $\mathrm{pH} 6.8)$ and then re-probed with rabbit polyclonal anti- $\beta$-actin (catalogue no. sc-130657; dilution 1:2000) to assure equal loading of protein. The DMT1 and FPN1 protein concentrations in each specimen were normalised to $\beta$-actin abundance.

\section{Statistical analysis}

Data were analysed by two-way ANOVA using the Glimmix procedure of SAS 9.2 (SAS Institute). The statistical model included the main effects of dietary Fe level, Mn source and their interaction. The individual animal served as the experimental unit ( $n 9$ or 6 per treatment). For all data, when the ANOVA was significant, post hoc comparisons of treatment means were carried out with Tukey's test. All data are presented as mean values with their standard errors. Statistical significance was assigned at $P<0.05$.

\section{Results}

\section{Performance}

Final body weight and body weight gain were higher $(P<0.03)$ in the MnLys-fed rats than in the $\mathrm{MnSO}_{4}$-fed rats (Table 2). The H-Fe diet decreased $(P<0.03)$ the final body weight and body weight gain as compared with the A-Fe diet. Feed intake was lower $(P=0.006)$ in $\mathrm{H}-\mathrm{Fe}$ rats and tended to be lower $(P<0 \cdot 10)$ in L-Fe rats than in A-Fe rats. Feed efficiency was not significantly affected by Mn source, dietary Fe level or their interaction.

\section{Blood or serum indices}

Serum Fe increased, whereas serum TIBC decreased $(P<0.05)$ with increasing dietary Fe concentration, irrespective of the Mn source (Table 3). Blood $\mathrm{Hb}$ also increased with increasing dietary $\mathrm{Fe}$ concentration, although blood $\mathrm{Hb}$ concentration in A-Fe rats did not differ in $\mathrm{H}-\mathrm{Fe}$ rats when fed the MnLys diet. Consumption of the MnLys diet increased $(P<0.05)$ blood $\mathrm{Hb}$ concentration as compared with the $\mathrm{MnSO}_{4}$ diet for A-Fe rats. Serum Mn was higher $(P<0.05)$ in rats fed the MnLys diet than in those fed the $\mathrm{MnSO}_{4}$ diet. The Mn source and interaction between the Mn source and dietary Fe concentration did not influence $(P>0 \cdot 10)$ blood $\mathrm{Hb}$, serum Fe and serum TIBC concentrations in rats.

\section{Iron and manganese concentrations in duodenum and liver}

Duodenal Mn concentrations were greater $(P<0.001)$ in rats fed the MnLys diet than in those fed the $\mathrm{MnSO}_{4}$ diet (Table 4). The A-Fe and $\mathrm{H}-\mathrm{Fe}$ rats had reduced $(P<0 \cdot 001)$ duodenal Mn concentrations as compared with L-Fe rats. Duodenal Mn concentrations in the A-Fe or H-Fe with MnLys groups were similar to the values in the $\mathrm{L}-\mathrm{Fe}$ with $\mathrm{MnSO}_{4}$ group. Liver Mn concentration was not affected $(P>0 \cdot 13)$ by $\mathrm{Mn}$ source, dietary Fe level and their interaction. The non-haeme $\mathrm{Fe}$ concentrations in duodenum and liver 
Table 2. Effect of dietary iron concentration and manganese source on performance of rats from 22 to $42 \mathrm{~d}$ of age (Mean values with their standard errors; $n$ 9)

\begin{tabular}{|c|c|c|c|c|c|c|c|c|c|c|c|c|c|c|c|}
\hline \multirow[b]{3}{*}{ Items } & \multicolumn{6}{|c|}{$\mathrm{MnSO}_{4}$} & \multicolumn{6}{|c|}{ MnLys } & & & \\
\hline & \multicolumn{2}{|c|}{ L-Fe } & \multicolumn{2}{|c|}{$\mathrm{A}-\mathrm{Fe}$} & \multicolumn{2}{|c|}{$\mathrm{H}-\mathrm{Fe}$} & \multicolumn{2}{|c|}{$\mathrm{L}-\mathrm{Fe}$} & \multicolumn{2}{|c|}{$\mathrm{A}-\mathrm{Fe}$} & \multicolumn{2}{|c|}{$\mathrm{H}-\mathrm{Fe}$} & \multicolumn{3}{|c|}{$P$} \\
\hline & Mean & SEM & Mean & SEM & Mean & SEM & Mean & SEM & Mean & SEM & Mean & SEM & Mn source & Fe level & Interaction \\
\hline IBW (g) & $56 \cdot 3$ & 1.62 & $57 \cdot 3$ & 0.92 & $57 \cdot 1$ & 0.88 & $57 \cdot 1$ & 0.71 & 57.6 & 1.32 & 57.5 & $1 \cdot 15$ & 0.580 & 0.797 & 0.977 \\
\hline FBW (g) & $136 \cdot 4$ & $4 \cdot 11$ & $136 \cdot 9$ & 4.55 & $130 \cdot 9^{*}$ & 4.74 & $140 \cdot 8$ & $5 \cdot 34$ & $156 \cdot 1$ & 3.80 & $136 \cdot 8^{*}$ & $6 \cdot 72$ & 0.013 & 0.036 & 0.285 \\
\hline BWG (g) & $80 \cdot 1$ & $4 \cdot 27$ & $79 \cdot 6$ & $4 \cdot 64$ & $73 \cdot 8^{*}$ & 4.94 & $83 \cdot 7$ & $5 \cdot 64$ & $98 \cdot 4$ & 3.96 & $79 \cdot 3^{*}$ & $7 \cdot 32$ & 0.024 & 0.054 & 0.311 \\
\hline $\mathrm{FI}(\mathrm{g})$ & $247 \cdot 6$ & $14 \cdot 3$ & $261 \cdot 2$ & $15 \cdot 3$ & $223 \cdot 4^{*}$ & $7 \cdot 56$ & $251 \cdot 2$ & $13 \cdot 2$ & $267 \cdot 1$ & $10 \cdot 5$ & $233 \cdot 7^{*}$ & $10 \cdot 5$ & 0.510 & 0.023 & 0.960 \\
\hline Gain:feed (g:g) & 0.32 & 0.02 & 0.30 & 0.02 & 0.31 & 0.02 & 0.33 & 0.02 & 0.37 & 0.02 & 0.34 & 0.03 & $0 \cdot 130$ & 0.878 & 0.372 \\
\hline
\end{tabular}

MnLys, Mn-lysine complex; L-Fe, the basal diet (2.68 mg Fe/kg); A-Fe, the basal diet supplemented with $35 \mathrm{mg}$ Fe/kg diet (adequate Fe level); H-Fe, the basal diet supplemented with $175 \mathrm{mg} \mathrm{Fe} / \mathrm{kg}$ diet (high Fe level); IBW, initial body weight; FBW, final body weight; BWG, body weight gain; FI, feed intake.

${ }^{*}$ Mean values differ from the corresponding A-Fe group, $P<0.05$.

Table 3. Effect of dietary iron concentration and manganese source on the blood or serum parameters of $42-\mathrm{d}$-old rats after $21 \mathrm{~d}$ of feeding (Mean values with their standard errors; $n 6$ )

\begin{tabular}{|c|c|c|c|c|c|c|c|c|c|c|c|c|c|c|c|}
\hline \multirow[b]{3}{*}{ Items } & \multicolumn{6}{|c|}{$\mathrm{MnSO}_{4}$} & \multicolumn{6}{|c|}{ MnLys } & & & \\
\hline & \multicolumn{2}{|c|}{$\mathrm{L}-\mathrm{Fe}$} & \multicolumn{2}{|c|}{$\mathrm{A}-\mathrm{Fe}$} & \multicolumn{2}{|c|}{$\mathrm{H}-\mathrm{Fe}$} & \multicolumn{2}{|c|}{$\mathrm{L}-\mathrm{Fe}$} & \multicolumn{2}{|c|}{$\mathrm{A}-\mathrm{Fe}$} & \multicolumn{2}{|c|}{$\mathrm{H}-\mathrm{Fe}$} & \multicolumn{3}{|c|}{$P$} \\
\hline & Mean & SEM & Mean & SEM & Mean & SEM & Mean & SEM & Mean & SEM & Mean & SEM & Mn source & Fe level & Interaction \\
\hline Blood Hb ( & $112 \cdot 3^{c}$ & 7.47 & $137 \cdot 4^{b}$ & $1 \cdot 76$ & $158 \cdot 1^{a}$ & 13.5 & $112 \cdot 0^{c}$ & $5 \cdot 10$ & $151 \cdot 3^{a}$ & 4.79 & $163 \cdot 2^{a}$ & $6 \cdot 68$ & 0.344 & $<0.001$ & 0.679 \\
\hline Serum TIBC ( $\mathrm{g} / \mathrm{l})$ & $140 \cdot 8^{\mathrm{a}}$ & $2 \cdot 22$ & $121 \cdot 3^{b}$ & $5 \cdot 38$ & $115 \cdot 5^{\mathrm{c}}$ & 8.91 & $139 \cdot 0^{\mathrm{a}}$ & 1.72 & $121 \cdot 3^{b}$ & 8.12 & $112 \cdot 3^{\mathrm{c}}$ & 5.38 & 0.391 & 0.003 & 0.738 \\
\hline Serum Fe (mg/l) & $14 \cdot 8^{\mathrm{C}}$ & 1.51 & $16 \cdot 7^{\mathrm{b}}$ & $1 \cdot 22$ & $18 \cdot 6^{a}$ & $1 \cdot 14$ & $15 \cdot 4^{\mathrm{C}}$ & 1.53 & $17 \cdot 1^{\mathrm{b}}$ & 1.33 & $19 \cdot 7^{a}$ & 1.52 & 0.546 & 0.005 & 0.745 \\
\hline Serum $\mathrm{Mn}(\mathrm{mg} / \mathrm{l})$ & $10 \cdot 7^{c}$ & 0.33 & $8 \cdot 63^{c}$ & 0.80 & $7 \cdot 05^{d}$ & 0.62 & $18 \cdot 0^{a}$ & $1 \cdot 12$ & $14 \cdot 1^{\mathrm{b}}$ & $2 \cdot 24$ & $14 \cdot 0^{\mathrm{b}}$ & 0.80 & $<0.001$ & 0.017 & 0.711 \\
\hline
\end{tabular}

MnLys, Mn-lysine complex; L-Fe, the basal diet (2.68 mg Fe/kg); A-Fe, the basal diet supplemented with $35 \mathrm{mg}$ Fe/kg diet (adequate Fe level); H-Fe, the basal diet supplemented with $175 \mathrm{mg} \mathrm{Fe} / \mathrm{kg}$ diet (high Fe level); TIBC, total Fe-binding capacity.

a,b,c,d Mean values within a column with unlike superscript letters were significantly different $(P<0.05)$.

Table 4. Effect of dietary iron concentration and manganese source on manganese and iron concentrations in the tissues of 42 -d-old rats after $21 \mathrm{~d}$ of feeding

(Mean values with their standard errors; $n 6$ )

\begin{tabular}{|c|c|c|c|c|c|c|c|c|c|c|c|c|c|c|c|}
\hline \multirow[b]{3}{*}{ Items } & \multicolumn{6}{|c|}{$\mathrm{MnSO}_{4}$} & \multicolumn{6}{|c|}{ MnLys } & \multirow{2}{*}{\multicolumn{3}{|c|}{$P$}} \\
\hline & \multicolumn{2}{|c|}{$\mathrm{L}-\mathrm{Fe}$} & \multicolumn{2}{|c|}{$\mathrm{A}-\mathrm{Fe}$} & \multicolumn{2}{|c|}{$\mathrm{H}-\mathrm{Fe}$} & \multicolumn{2}{|c|}{$\mathrm{L}-\mathrm{Fe}$} & \multicolumn{2}{|c|}{$\mathrm{A}-\mathrm{Fe}$} & \multicolumn{2}{|c|}{$\mathrm{H}-\mathrm{Fe}$} & & & \\
\hline & Mean & SEM & Mean & SEM & Mean & SEM & Mean & SEM & Mean & SEM & Mean & SEM & Mn source & Fe level & Interaction \\
\hline \multicolumn{16}{|c|}{$\mathrm{Mn}(\mu \mathrm{g} / \mathrm{g}$ wet tissue) } \\
\hline Duodenum & $1.24^{b}$ & 0.05 & $1.06^{\mathrm{d}}$ & 0.01 & $1.08^{c, d}$ & 0.06 & $1.94^{\mathrm{a}}$ & 0.06 & $1 \cdot 22^{\mathrm{b}, \mathrm{c}}$ & 0.06 & $1.24^{\mathrm{b}}$ & 0.04 & $<0.001$ & $<0.001$ & $<0.001$ \\
\hline Liver & $2 \cdot 68$ & 0.17 & $2 \cdot 39$ & 0.08 & $2 \cdot 12$ & 0.11 & $2 \cdot 60$ & 0.13 & $2 \cdot 54$ & 0.22 & 2.47 & 0.19 & 0.288 & 0.132 & 0.422 \\
\hline \multicolumn{16}{|c|}{ Non-haeme $\mathrm{Fe}(\mu \mathrm{g} / \mathrm{g}$ wet tissue) } \\
\hline Duodenum & $22 \cdot 2^{d}$ & 1.29 & $61 \cdot 5^{\mathrm{b}}$ & $4 \cdot 08$ & $93 \cdot 7^{\mathrm{a}}$ & 3.08 & $21 \cdot 4^{d}$ & 0.62 & $51 \cdot 3^{c}$ & 1.51 & $90 \cdot 7^{\mathrm{a}}$ & $2 \cdot 28$ & 0.028 & $<0.001$ & $0 \cdot 156$ \\
\hline Liver & $20 \cdot 6^{c}$ & 1.04 & $73 \cdot 2^{b}$ & 4.09 & $110 \cdot 1^{a}$ & 4.69 & $20 \cdot 5^{c}$ & 0.78 & $69 \cdot 7^{b}$ & $13 \cdot 3$ & $102 \cdot 6^{\mathrm{a}}$ & 6.07 & 0.495 & $<0.001$ & 0.856 \\
\hline
\end{tabular}

MnLys, Mn-lysine complex; L-Fe, the basal diet (2.68 mg Fe/kg); A-Fe, the basal diet supplemented with 35 mg Fe/kg diet (adequate Fe level); H-Fe, the basal diet supplemented with $175 \mathrm{mg} \mathrm{Fe} / \mathrm{kg}$ diet (high Fe level).

a,b,c,d Mean values within a column with unlike superscript letters were significantly different $(P<0.05)$.

increased $(P<0.001)$ from L-Fe to A-Fe to H-Fe rats. Duodenal non-haeme $\mathrm{Fe}$ concentrations were lower $(P=0.007)$ in the MnLys treatment group than in the $\mathrm{MnSO}_{4}$ treatment group for A-Fe rats, but it did not differ $(P>0 \cdot 15)$ between the two Mn sources for L-Fe or H-Fe rats. The Mn source did not influence $(P>0 \cdot 10)$ liver Fe concentrations.

\section{Gene expression in the duodenum and liver}

In the duodenum, the relative abundance of DMT1 mRNA was lower $(P<0.001)$ in A-Fe or H-Fe rats compared with L-Fe rats. Duodenal DMT1 mRNA was greater $(P<0.04)$ in the MnLys group than in the $\mathrm{MnSO}_{4}$ group for A-Fe rats, but no significant difference was observed $(P>0 \cdot 10)$ between the two Mn sources for L-Fe or H-Fe rats (Fig. 1(a)). Duodenal FPN1 mRNA was not influenced $(P>0 \cdot 20)$ by Mn source, dietary Fe level or their interaction (Fig. 1(a)).

In the liver, the relative abundance of DMT1 mRNA was higher $(P<0 \cdot 001)$ in the MnLys group than in the $\mathrm{MnSO}_{4}$ group for $\mathrm{H}-\mathrm{Fe}$ rats, whereas no significant difference was observed $(P>0 \cdot 10)$ between the two Mn sources for L-Fe or A-Fe-fed rats (Fig. 2(a)). The expression of FPN1 mRNA was lower $(P<0 \cdot 001)$ in A-Fe and $\mathrm{H}-\mathrm{Fe}$ rats than in L-Fe rats (Fig. 2(a)). Consumption of the MnLys diet tended to decrease $(P=0.056)$ hepatic FPN1 mRNA as 
(A)

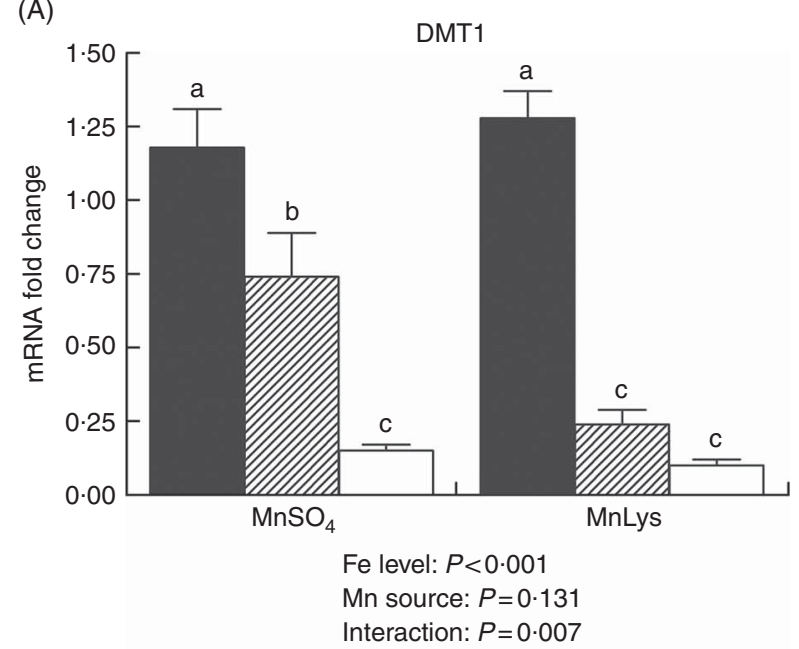

(B)

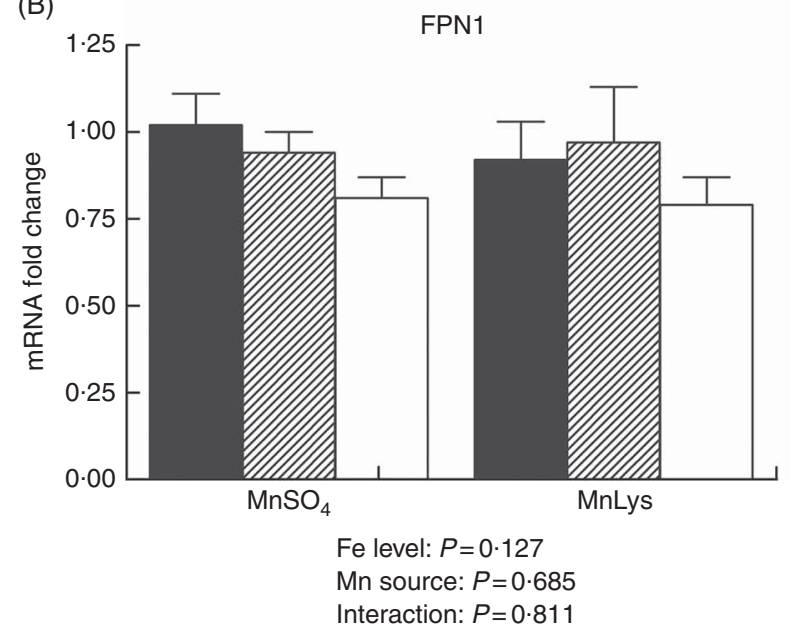

Fig. 1. Effect of dietary Fe concentration and $M n$ source on the mRNA abundance of divalent metal transporter-1 (DMT1) (A) and ferroportin 1 (FPN1) (B) in the duodenum of rats. The weanling rats (22-d-old) were fed the basal diet (L-Fe; containing $2.68 \mathrm{mg} \mathrm{Fe} / \mathrm{kg}$ ) or the basal diet supplemented with $35 \mathrm{mg} / \mathrm{kg}$ (A-Fe) or $175 \mathrm{mg} / \mathrm{kg}(\mathrm{H}-\mathrm{Fe}$ ) Fe in combination with $10 \mathrm{mg} / \mathrm{kg} \mathrm{Mn}$ (adequate level) from $\mathrm{MnSO}_{4}$ or $\mathrm{Mn}$-lysine complex (MnLys) for $21 \mathrm{~d}$. The mRNA abundance was determined by real-time quantitative PCR. Data are presented in arbitrary units as relative mRNA abundance normalised to $\beta$-actin transcript abundance, and the average expression of duodenal target gene mRNA relative to the average of the L-Fe with $\mathrm{MnSO}_{4}$ group as a calibrator. Data were analysed by two-way ANOVA, and the statistical model included the main effects of dietary Fe level, Mn source and their interaction. The post hoc comparisons of treatment means were carried out with Tukey's test. Values are means with their standard errors represented by vertical bars. a,b,c Mean values $(n 6)$ with unlike letters were significantly different $(P<0.05)$. $\square$, L-Fe; 诸, A-Fe; $\square, \mathrm{H}-\mathrm{Fe}$.

compared with consumption of the $\mathrm{MnSO}_{4}$ diet. Liver TFR1 mRNA decreased $(P<0.001)$, whereas HAMP mRNA increased $(P<0.001)$ from L-Fe to A-Fe rats, to $\mathrm{H}-\mathrm{Fe}$ rats, irrespective of the Mn source (Fig. 2(c) and (d)). The Mn source and interaction between the Mn source and dietary Fe did not affect $(P>0 \cdot 30)$ hepatic expression of TFR1 and HAMP mRNA.

\section{Transporter protein abundance}

Duodenal DMT1 and FPN1 protein decreased $(P<0.001)$ in $\mathrm{H}-\mathrm{Fe}$ rats as compared with L-Fe rats (Fig. 3). Duodenal DMT1 protein was lower $(P<0.001)$ in the MnLys group than in the $\mathrm{MnSO}_{4}$ group for A-Fe rats, but it did not differ $(P>0 \cdot 10)$ between the two Mn sources for L-Fe or H-Fe rats (Fig. 3(a)). Duodenal FPN1 protein was lower $(P<0.001)$ in rats that were fed the MnLys diet compared with the $\mathrm{MnSO}_{4}$ diet in combination with A-Fe or H-Fe treatment, but it did not differ $(P>0 \cdot 10)$ between the two Mn sources in rats that consumed the L-Fe diet (Fig. 3(b)). The apparent molecular mass of DMT1 and FPN1 as estimated by SDS-PAGE was approximately 53 and $64 \mathrm{kDa}$, respectively, similar to the predicted molecular weight based on the amino acid sequence of rat DMT1 $(52 \mathrm{kDa})$ and FPN $(62 \mathrm{kDa})^{(25)}$.

Liver DMT1 protein was lower $(P<0 \cdot 001)$ in A-Fe or $\mathrm{H}-\mathrm{Fe}$ rats than in L-Fe rats (Fig. 4(a)). Consumption of the MnLys diet decreased $(P=0.004)$ hepatic DMT1 protein compared with the $\mathrm{MnSO}_{4}$ diet at all dietary Fe concentrations. The FPN1 protein decreased $(P<0.05)$ with increasing dietary Fe concentration in rats that consumed the $\mathrm{MnSO}_{4}$ diet, whereas no difference $(P>0 \cdot 10)$ was observed in rats fed the MnLys diet with different Fe concentrations (Fig. 4(b)). Consumption of the MnLys diet decreased $(P<0.05)$ liver FPN1 protein as compared with the $\mathrm{MnSO}_{4}$ diet for L-Fe, whereas there was no difference $(P>0 \cdot 12)$ between the Mn sources for A-Fe or H-Fe rats.

\section{Discussion}

The weanling rats display rapid growth and thus have a high demand for $\mathrm{Fe}$; therefore, the practical diets often contain concentrations exceeding Fe requirements. In this study, we fed the rats with the $\mathrm{L}-\mathrm{Fe}$ diet $(2.68 \mathrm{mg} \mathrm{Fe} / \mathrm{kg}$ diet $)$ for $21 \mathrm{~d}$ to achieve an Fe deficiency as evaluated by traditional measures of $\mathrm{Fe}$ status ( $\mathrm{Hb}$ and serum $\mathrm{Fe}$ ), consistent with a previous report that feeding an Fe-deficient diet to rats for $17 \mathrm{~d}$ led to anaemia $^{(26)}$. The H-Fe diet increased the Fe status in rats, whereas increased $\mathrm{Hb}$ concentrations were still within the normal physiological range (137-176g/l) in the present study $^{(27,28)}$. However, the $\mathrm{H}-\mathrm{Fe}$ diet decreased the growth performance of rats during the 21-d experimental period relative to the A-Fe diet.

The DMT1 appears to be the predominate protein involved in non-transferrin bound $\mathrm{Fe}^{2+}$ uptake by the cell ${ }^{(29,30)}$. In this study, the increase in intestinal DMT1 mRNA and protein expression in L-Fe rats was likely reflective of the rat's L-Fe status and increased need for dietary Fe to meet their requirements. We also found a strong negative correlation between liver Fe concentration and duodenal DMT1 expression in H-Fe rats, suggesting that the high body Fe stores were signalling reductions in intestinal $\mathrm{Fe}$ transport ${ }^{(8)}$. In recent years, the liverderived hormone HAMP has emerged as the link between Fe stores and regulation of intestinal Fe transport ${ }^{(31)}$. Marked increases in HAMP mRNA expression in the liver of $\mathrm{H}-\mathrm{Fe}$ rats reflect $\mathrm{H}$-Fe stores, resulting in the reduction of intestinal Fe transport into circulation. HAMP binds to FPN1 on the basolateral membrane of enterocytes, causing FPN1 to be internalised and degraded to decrease export of $\mathrm{Fe}$ into plasma $^{(32)}$. Concurrent with the rise in hepatic HAMP expression, the decrease in intestinal FPN1 protein in H-Fe rats in the 
(A)

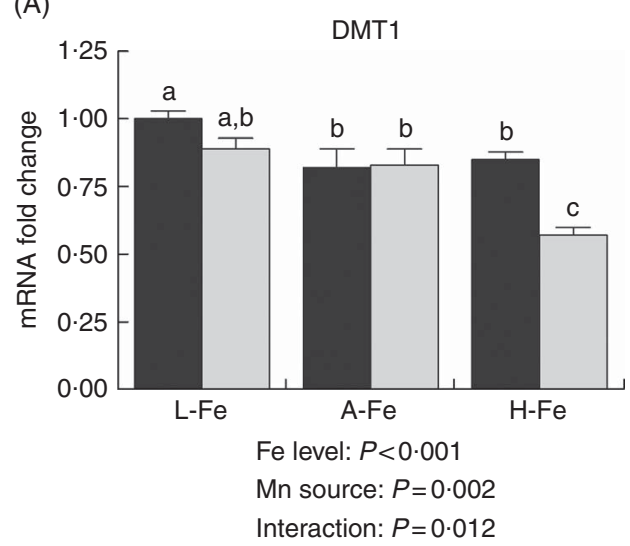

(C)

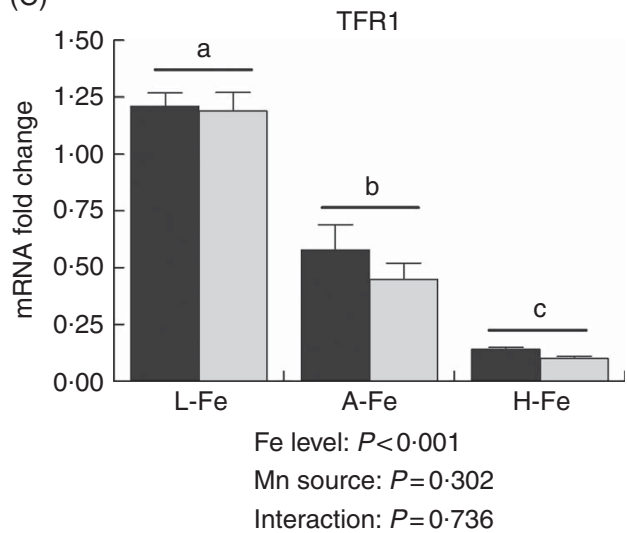

(B)

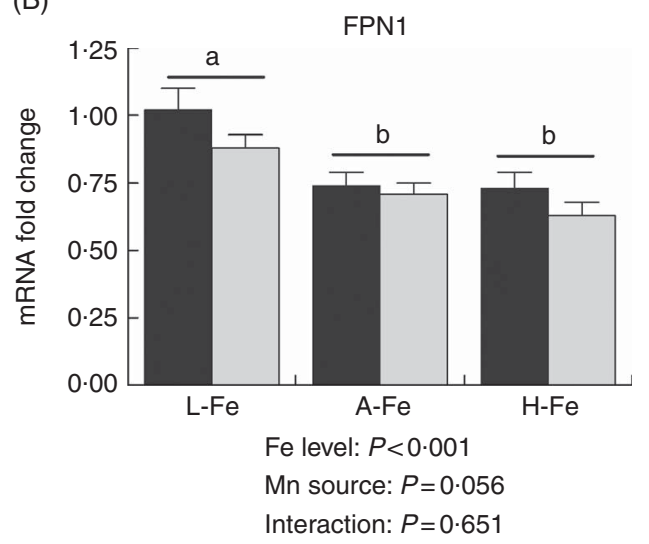

(D)

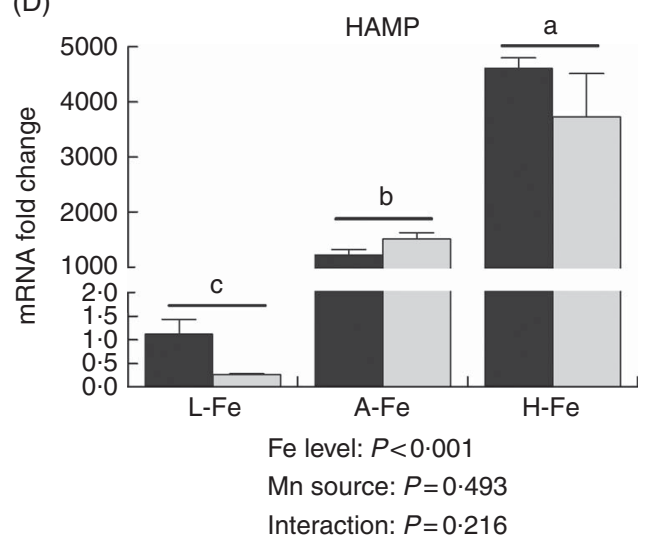

Fig. 2. Effect of dietary Fe concentration and Mn source on the mRNA abundance of divalent metal transporter-1 (DMT1) (A), ferroportin 1 (FPN1) (B), transferrin receptor 1 (TFR1) (C) and hepcidin (HAMP) (D) in the liver of rats. The weanling rats (22-d-old) were fed the basal diet (L-Fe; containing 2.68 mg Fe/kg) or the basal diet supplemented with $35 \mathrm{mg} / \mathrm{kg}$ (A-Fe) or $175 \mathrm{mg} / \mathrm{kg}\left(\mathrm{H}-\mathrm{Fe}\right.$ ) Fe in combination with $10 \mathrm{mg} / \mathrm{kg} \mathrm{Mn} \mathrm{(adequate} \mathrm{level)} \mathrm{from} \mathrm{MnSO} \mathrm{M}_{4}$ or Mn-lysine complex (MnLys) for $21 \mathrm{~d}$. The mRNA abundance was determined by real-time quantitative PCR. Data are presented in arbitrary units as relative mRNA abundance normalised to $\beta$-actin transcript abundance, and the average expression of duodenal target gene mRNA in the L-Fe with $\mathrm{MnSO}_{4}$ group was used as a calibrator. Data were analysed by twoway ANOVA, and the statistical model included the main effects of dietary Fe level, Mn source and their interaction. The post hoc comparisons of treatment means were carried out with Tukey's test. Values are means with their standard errors represented by vertical bars. ${ }^{\mathrm{a}, \mathrm{b}, \mathrm{c}}$ Mean values $(n 6)$ with unlike letters were significantly different $(P<0.05)$. $\square, \mathrm{MnSo}_{4} ; \square$, MnLys.

present study also suggested that the hepcidn-FPN1 axis has an important role in Fe haemostasis regulation ${ }^{(33)}$. However, consumption of the $\mathrm{H}-\mathrm{Fe}$ diet for $21 \mathrm{~d}$ was not associated with decreased duodenal FPN1 mRNA in this study, inconsistent with the previous reports that short-term (4-10 d) Fe loading reduced intestinal FPN1 mRNA in mice ${ }^{(34,35)}$. This discrepancy was likely because of the difference in Fe loading term, as McKie et al. ${ }^{(35)}$ reported that intestinal FPN1 mRNA expression was not regulated in mice by chronic dietary Fe loading ( 4 weeks). The results presented herein show that the major mechanism of regulating intestinal FPN1 expression is translational regulation. Body HAMP secreted by the liver in response to high serum Fe down-regulated FPN1 at the protein level ${ }^{(33)}$ and thereby limited Fe absorption from the diet in H-Fe rats.

Dietary Fe concentration may interfere with tissue metabolism of other trace elements including $\mathrm{Mn}^{(8,36,37)}$. In this study, consumption of the L-Fe diet increased Mn status as indicated by the biomarker of Mn availability (serum Mn) ${ }^{(36,38)}$, as compared with the A-Fe and H-Fe diets. The decrease in serum Mn suggests that the $\mathrm{H}-\mathrm{Fe}$ diet decreased intestinal Mn absorption, consistent with what has been reported for pigs and calves ${ }^{(8,37)}$. However, as compared with the L-Fe diet, consumption of the $\mathrm{H}-\mathrm{Fe}$ diet did not alter liver Mn concentrations in the present study. The liver has a vital role in regulating Mn levels because in vivo studies showed that the liver is the major route for Mn elimination ${ }^{(39-41)}$. Increased serum Mn was associated with greater biliary $\mathrm{Mn}$ excretion in rats ${ }^{(39,40)}$. In the present study, no difference in liver $\mathrm{Mn}$ retention could be because of the difference in Mn excretion in rats with a different Fe status.

In addition to transporting Fe, DMT1 ${ }^{(13,36)}$ and FPN1 $1^{(15,18)}$ can transport several other divalent metals, including $\mathrm{Mn}$. In this study, the $\mathrm{H}-\mathrm{Fe}$ diet decreased $\mathrm{Mn}$ concentrations in the serum and duodenum, and down-regulated duodenal DMT1 and FPN1 protein expression as compared with the L-Fe diet, suggesting a possible role for DMT1 and FPN1 in the antagonism between $\mathrm{Fe}$ and $\mathrm{Mn}$ in the intestine of rats. It is possible that the reduction in serum Mn concentrations resulted from a combination of reduced intestinal DMT1 and FPN1 expression and increased competition between $\mathrm{Fe}$ and $\mathrm{Mn}$ for uptake in $\mathrm{H}-\mathrm{Fe}$ rats. The decrease in duodenal Mn concentration 
(A)

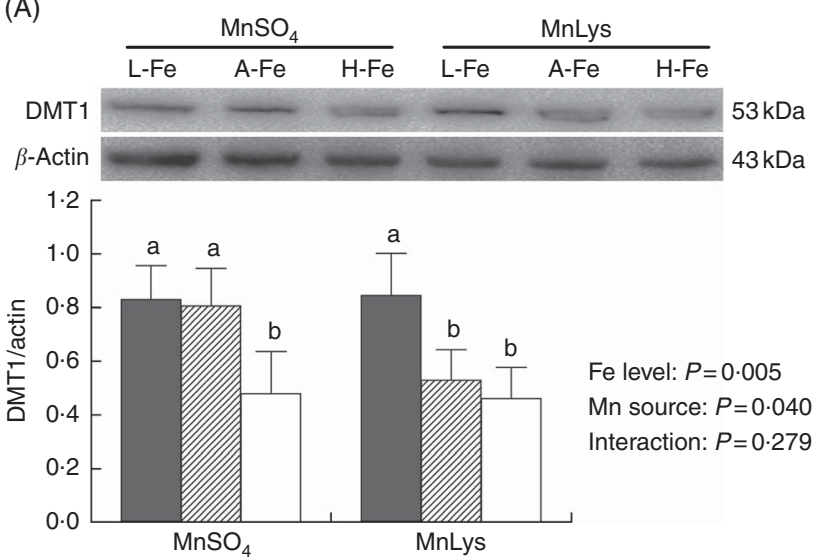

(B)
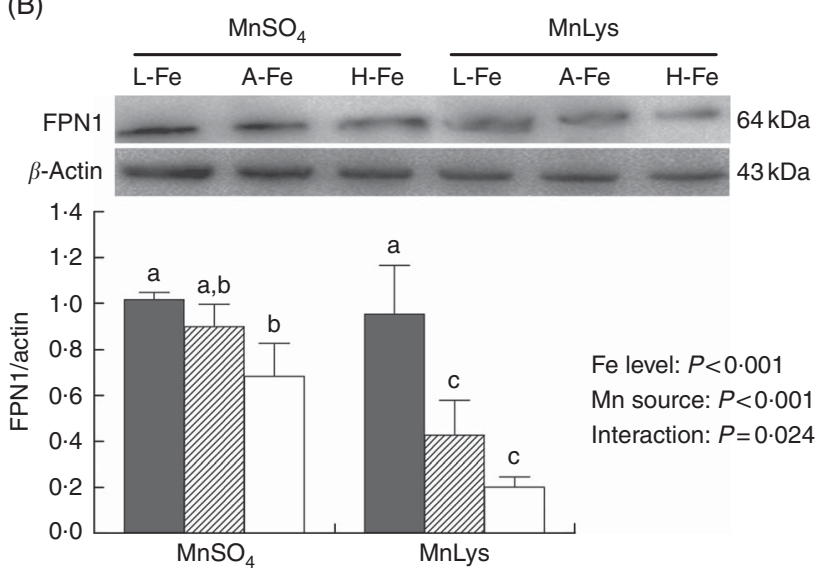

Fe level: $P<0.001$

Mn source: $P<0.001$

Interaction: $P=0.024$

Fig. 3. Effect of dietary $\mathrm{Fe}$ concentration and $\mathrm{Mn}$ source on the protein expression of divalent metal transporter-1 (DMT1) (A) and ferroportin 1 (FPN1) (B) in the duodenum of rats. The weanling rats (22-d-old) were fed the basal diet (L-Fe; containing $2.68 \mathrm{mg} \mathrm{Fe} / \mathrm{kg}$ ) or the basal diet supplemented with $35(\mathrm{~A}-\mathrm{Fe})$ or $175(\mathrm{H}-\mathrm{Fe}) \mathrm{mg} / \mathrm{kg} \mathrm{Fe}$ in combination with $10 \mathrm{mg} / \mathrm{kg} \mathrm{Mn}$ (adequate level) from $\mathrm{MnSO}_{4}$ or Mn-lysine complex (MnLys) for $21 \mathrm{~d}$. The DMT1 and FPN1 protein quantities were determined by western blotting. Data are presented in arbitrary units relative to $\beta$-actin protein. Data were analysed by two-way ANOVA, and the statistical model included the main effects of dietary Fe level, Mn source and their interaction. The post hoc comparisons of treatment means were carried out with Tukey's test. Values are means with their standard errors represented by vertical bars. ${ }^{\mathrm{a}, \mathrm{b}, \mathrm{c}}$ Means $(n 6)$ with unlike letters were significantly different $(P<0.05)$. Representative blots of DMT1, FPN1 and $\beta$-actin are shown. $\square, \mathrm{L}-\mathrm{Fe}$; 贯, A-Fe; $\square, \mathrm{H}-\mathrm{Fe}$.

in rats that consumed the H-Fe diet was partially because of decreased duodenal DMT1 expression.

Neither the Association of Official Analytical Chemists ${ }^{(42)}$ nor the Association of American Feed Control Officials ${ }^{(43)}$ has approved specific methods to test the complex bonding of a mineral element to an organic ligand. No direct evidence about the mechanism of $\mathrm{Mn}$ absorption from a Mn-amino acid chelate is reported. Therefore, we indirectly studied the absorption of Mn from different Mn sources under different Fe status. The results presented herein showed that the $\mathrm{H}-\mathrm{Fe}$ diet decreased the availability of $\mathrm{Mn}$ from $\mathrm{MnSO}_{4}$ and MnLys, which suggests that the Mn from MnLys was at least partly absorbed as ionised $\mathrm{Mn}^{2+}$ through intestinal Fe transporters. However, the MnLys was more bioavailable than $\mathrm{MnSO}_{4}$ for the weaning rats, as demonstrated by the biomarker of Mn availability (serum Mn).
(A)

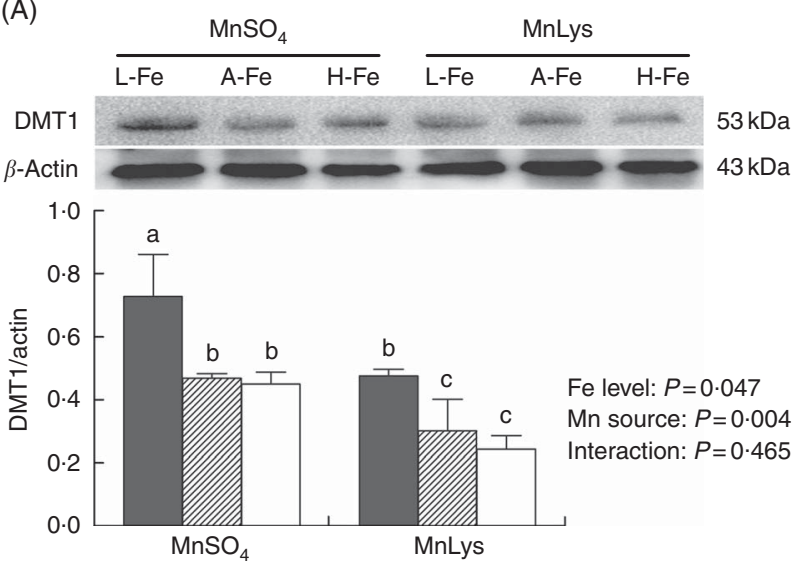

(B)
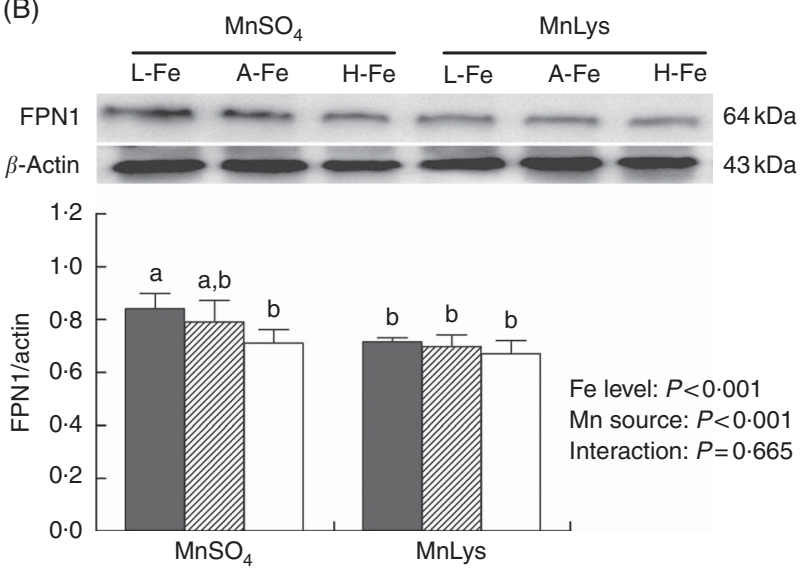

Fig. 4. Effect of dietary Fe concentration and $\mathrm{Mn}$ source on the protein abundance of divalent metal transporter-1 (DMT1) (A) and ferroportin 1 (FPN1) (B) in the liver of rats. The weanling rats (22-d-old) were fed the basal diet (L-Fe; containing $2.68 \mathrm{mg} \mathrm{Fe} / \mathrm{kg}$ ) or the basal diet supplemented with $35 \mathrm{mg} / \mathrm{kg}$ $(\mathrm{A}-\mathrm{Fe})$ or $175 \mathrm{mg} / \mathrm{kg}(\mathrm{H}-\mathrm{Fe}) \mathrm{Fe}$ in combination with $10 \mathrm{mg} / \mathrm{kg} \mathrm{Mn}$ (adequate level) from $\mathrm{MnSO}_{4}$ or Mn-lysine complex (MnLys) for $21 \mathrm{~d}$. The DMT1 and FPN1 proteins were determined by western blotting. Data are presented in arbitrary units relative to $\beta$-actin protein. Data were analysed by two-way ANOVA, and the statistical model included the main effects of dietary Fe level, $\mathrm{Mn}$ source and their interaction. The post hoc comparisons of treatment means were carried out with Tukey's test. Values are means with their standard errors represented by vertical bars. ${ }^{a, b, c}$ Means $(n 6)$ with unlike letters were significantly different $(P<0.05)$. Representative blots of DMT1, FPN1 and $\beta$-actin are shown. $\square, \mathrm{L}-\mathrm{Fe} ; \mathbb{U}_{\mathrm{C}}, \mathrm{A}-\mathrm{Fe} ; \square, \mathrm{H}-\mathrm{Fe}$.

This result is consistent with previous studies in broiler chickens ${ }^{(21,22)}$. The MnLys could resist interference from dietary and nutritional factors such as phosphate, phytate and other compounds to bind ionised $\mathrm{Mn}$ in the digestive tract and directly reach the intestinal brush border, where it is hydrolysed and is more likely to bind transporters ${ }^{(44)}$, which might partially explain the increased availability of Mn from a MnLys complex. However, our data showed that the MnLys diet reduced duodenal DMT1 and FPN1 protein expression in rats as compared with the $\mathrm{MnSO}_{4}$ diet. A decrease in DMT1 expression was observed in ligated duodenal loops of chickens ${ }^{(22)}$ and Caco-2 cells ${ }^{(11)}$ after treatment with relatively high concentrations of Mn. It is possible that the higher serum Mn induced the down-regulation of intestinal DMT1 and FPN1 expression, as described by Bai et al. ${ }^{(45)}$, who reported that greater plasma 
Mn was associated with decreased DMT1 and FPN1 transcription in hens. The decrease in duodenal DMT1 and FPN1 may decrease intestinal Mn export to the serum in MnLys rats, which suggests that DMT1 and FPN1 were not responsible for the greater bioavailability of Mn from MnLys. Ashmead et al. ${ }^{(46)}$ reported that the complexed or chelated minerals can be absorbed intact, and that the metal atoms remain safely bound or protected within the organic molecular structure or ligands during absorption. The amino acid carriers are involved in the transport of $\mathrm{Cu}$ in the $\mathrm{Cu}$-amino acid complex, as shown using the Caco- 2 cell line model ${ }^{(47)}$. It is possible that there are other transporters or transport systems involved in the uptake of MnLys, which then contributes to the relatively higher serum Mn concentration in MnLys rats.

In conclusion, dietary Fe concentration affected the availability of Mn regardless of the Mn source, and MnLys was more bioavailable than $\mathrm{MnSO}_{4}$ in the small intestine of rats. However, consumption of the MnLys diet, as compared with $\mathrm{MnSO}_{4}$, was associated with decreased expression of DMT1 and FPN1 protein in the duodenum, which might decrease Mn transport from the MnLys complex. These results suggest that there are other transporters or transport pathways for the MnLys complex in the small intestine of rats.

\section{Acknowledgements}

The present study was supported by the Program of the National Natural Science Foundation of China (grant number 31001018), and Specific Research Team Supporting Program of Sichuan Agricultural University (grant number SAU2012SRTSP12).

H. Z. and S. B. designed the research. H. Z., J. W. and Q. Z. conducted the research. E. R. G., K. Z, X. D and S. B. collected and analysed data. H. Z., E. R. G. and S. B. wrote the paper. All authors read and approved the final manuscript.

The authors declare that they have no conflicts of interest.

\section{Supplementary material}

For supplementary material/s referred to in this article, please visit http://dx.doi.org/doi:10.1017/S0007114515004900

\section{References}

1. Umbreit J (2005) Iron deficiency: a concise review. $A m J$ Hematol 78, 225-231.

2. Siega-Riz AM, Hartzema AG, Turnbull C, et al. (2006) The effects of prophylactic iron given in prenatal supplements on iron status and birth outcomes: a randomized controlled trial. Am J Obstet Gynecol 194, 512-519.

3. Pathak P, Kapil U, Kapoor SK, et al. (2004) Prevalence of multiple micronutrient deficiencies amongst pregnant women in a rural area of Haryana. Indian J Pediatr 71, 1007-1014.

4. Duque X, Flores-Hernández S, Flores-Huerta S, et al. (2006) Prevalence of anemia and deficiency of iron, folic acid, and zinc in children younger than 2 years of age who use the health services provided by the Mexican Social Security Institute. BMC Public Health 7, 345.

5. Knovich MA, Il'yasova D, Ivanova A, et al. (2008) The association between serum copper and anaemia in the adult
Second National Health and Nutrition Examination Survey (NHANES II) population. Br J Nutr 99, 1226-1229.

6. Thompson K, Molina R, Donaghey T, et al. (2006) The influence of high iron diet on rat lung manganese absorption. Toxicol Appl Pharmacol 210, 17-23.

7. Davis CD, Wolf TL \& Greger JL (1992) Varying levels of manganese and iron affect absorption and gut endogenous losses of manganese by rats. J Nutr 122, 1300-1308.

8. Hansen SL, Trakooljul N, Liu HC, et al. (2009) Iron transporters are differentially regulated by dietary iron, and modifications are associated with changes in manganese metabolism in young pigs. J Nutr 139, 1474-1479.

9. Jolliff JS \& Mahan DC (2012) Effect of dietary inulin and phytase on mineral digestibility and tissue retention in weanling and growing swine. J Anim Sci 90, 3012-3022.

10. Liu Y, Ma YL, Zhao JM, et al. (2014) Digestibility and retention of zinc, copper, manganese, iron, calcium, and phosphorus in pigs fed diets containing inorganic or organic minerals. J Anim Sci $92,3407-3415$.

11. Li X, Xie J, Lu L, et al. (2013) Kinetics of manganese transport and gene expressions of manganese transport carriers in Caco-2 cell monolayers. Biometals 26, 941-953.

12. Fleming MD, Romano MA, Su MA, et al. (1998) Nramp2 is mutated in the anemic Belgrade (b) rat evidence of a role for Nramp2 in endosomal iron transport. Proc Natl Acad Sci USA 95, 1148-1153.

13. Gunshin H, Allerson CR, Polycarpou-Schwarz M, et al. (2001) Iron-dependent regulation of the divalent metal ion transporter. FEBS Lett 509, 309-316.

14. Thompson K, Molina RM, Donaghey T, et al. (2007) Olfactory uptake of manganese requires DMT1 and is enhanced by anemia. FASEB J 21, 223-230.

15. Kim J, Li Y, Buckett PD, et al. (2012) Iron-responsive olfactory uptake of manganese improves motor function deficits associated with iron deficiency. PLOS ONE 7, e33533.

16. Illing AC, Shawki A, Cunningham CL, et al. (2012) Substrate profile and metal-ion selectivity of human divalent metal-ion transporter-1. J Biol Chem 287, 30485-30496.

17. Yin Z, Jiang H, Lee ES, et al. (2010) Ferroportin is a manganese-responsive protein that decreases manganese cytotoxicity and accumulation. J Neurochem 112, 1190-1198.

18. Madejczyk MS \& Ballatori N (2012) The iron transporter ferroportin can also function as a manganese exporter. Biochim Biophys Acta 1818, 651-657.

19. Ashmead HD (2012) Amino Acid Chelation in Human and Animal Nutrition. Boca Raton, FL: CRC Press.

20. Reeves PG, Rossow KL \& Lindlauf J (1993) Development and testing of the AIN-93 purified diets for rodents: results on growth, kidney calcification and bone mineralization in rats and mice. J Nutr 123, 1923-1931.

21. Bai SP, Lu L, Luo XG, et al. (2008) Kinetics of manganese absorption in ligated small intestinal segments of broilers. Poult Sci 87, 2596-2604.

22. Bai SP, Lu L, Wang RL, et al. (2012) Manganese source affects manganese transport and gene expression of divalent metal transporter 1 in the small intestine of broilers. Br J Nutr $\mathbf{1 0 8}$, 267-276.

23. Brain JD, Heilig E, Donaghey TC, et al. (2006) Effects of iron status on transpulmonary transport and tissue distribution of Mn and Fe. Am J Respir Cell Mol Biol 34, 330-337.

24. Livak KJ \& Schmittgen TD (2001) Analysis of relative gene expression data using real-time quantitative PCR and the 2(-Delta Delta C (T)) method. Methods 25, 402-408.

25. Urrutia P, Aguirre P, Esparza A, et al. (2013) Inflammation alters the expression of DMT1, FPN1 and hepcidin, and it causes iron accumulation in central nervous system cells. J Neurochem 126, 541-549. 
26. Kamei A, Watanabe Y, Ishijima T, et al. (2010) Dietary irondeficient anemia induces a variety of metabolic changes and even apoptosis in rat liver: a DNA microarray study. Physiol Genomics 42, 149-156.

27. Azebedo JL, Willis WT, Turcotte LP, et al. (1989) Reciprocal changes of muscle oxidases and liver enzymes with recovery from iron deficiency. Am J Physiol 256, E401-E 405.

28. Klempa KL, Willis WT, Chengson R, et al. (1989) Iron deficiency decreases gluconeogenesis in isolated rat hepatocytes. $J$ Appl Physiol 67, 1868-1872.

29. Zoller H, Theurl I, Koch R, et al. (2002) Mechanisms of iron mediated regulation of the duodenal iron transporters divalent metal transporter 1 and ferroportin 1. Blood Cells Mol Dis 29, 488-497.

30. Foot NJ, Dalton HE, Shearwin-Whyatt LM, et al. (2008) Regulation of the divalent metal ion transporter DMT1 and iron homeostasis by a ubiquitin-dependent mechanism involving Ndfips and WWP2. Blood 112, 4268-4275.

31. Nemeth E, Tuttle MS, Powelson J, et al. (2004) Hepcidin regulates cellular iron efflux by binding to ferroportin and inducing its internalization. Science 306, 2090-2093.

32. De Domenico I, Ward DM, Langelier C, et al. (2007) The molecular mechanism of hepcidin-mediated ferroportin down-regulation. Mol Biol Cell 18, 2569-2578.

33. Nemeth E \& Ganz T (2006) Regulation of iron metabolism by hepcidin. Annu Rev Nutr 26, 323-342.

34. Abboud S \& Haile DJ (2000) A novel mammalian iron-regulated protein involved in intracellular iron metabolism. $J$ Biol Chem 275, 19906-19912.

35. McKie AT, Marciani P, Rolfs A, et al. (2000) A novel duodenal iron-regulated transporter, IREG1, implicated in the basolateral transfer of iron to the circulation. Mol Cell 5, 299-309.

36. Roth JA \& Garrick MD (2003) Iron interactions and other biological reactions mediating the physiological and toxic actions of manganese. Biochem Pharmacol 66, 1-13.
37. Hansen SL, Ashwell MS, Moeser AJ, et al. (2010) High dietary iron reduces transporters involved in iron and manganese metabolism and increases intestinal permeability in calves. J Dairy Sci 93, 656-665.

38. Ji F, Luo XG, Lu L, et al. (2006) Effects of manganese source and calcium on manganese uptake by in vitro everted gut sacs of broilers' intestinal segments. Poult Sci 85, 1217-1225.

39. Davis CD, Zech L \& Greger JL (1993) Manganese metabolism in rats: an improved methodology for assessing gut endogenous losses. Proc Soc Exp Biol Med 202, 103-108.

40. Malecki EA, Radzanowski GM, Radzanowski TJ, et al. (1996) Biliary manganese excretion in conscious rats is affected by acute and chronic manganese intake but not by dietary fat. J Nutr 126, 489-498.

41. Roth JA (2006) Homeostatic and toxic mechanisms regulating manganese uptake, retention, and elimination. Biol Res 39, $45-57$.

42. Patricia C (editor) (1995) Official Methods of Analysis of AOAC International. Arlington, VA: AOAC International.

43. Association of American Feed Control Officials (2001) Official Publication. Atlanta, GA: Association of American Feed Control Official Incorporated Company.

44. Ji F, Luo XG, Lu L, et al. (2006) Effect of manganese source on manganese absorption by the intestine of broilers. Poult Sci 85, 812-822.

45. Bai S, Huang L, Luo Y, et al. (2014) Dietary manganese supplementation influences the expression of transporters involved in iron metabolism in chickens. Biol Trace Elem Res 160, 352-360.

46. Ashmead HD (1993) Comparative intestinal absorption and subsequent metabolism of metal amino acid chelates and inorganic metal salts. In The Roles of Amino Acid Chelates in Animal Nutrition, pp. 47-74 [HD Ashmead, editor]. Park Ridge, NJ: Noyes Publications.

47. Gao S, Yin T, Xu B, et al. (2014) Amino acid facilitates absorption of copper in the Caco-2 cell culture model. Life Sci 109, 50-56. 